\title{
How Do Students Perceive the Difficulty of Physics in Secondary School? An Exploratory Study in Nigeria
}

\author{
Stella Y. Erinosho \\ Olabisi Onabanjo University \\ Nigeria
}

\begin{abstract}
This study aimed at identifying the areas of physics that students considered as posing difficulty and what account for this difficulty. A questionnaire was administered to 830 (306 females and 524 males) final year students in science class and 52 physics teachers purposively drawn from secondary schools in Ogun and Lagos States, Nigeria. The findings show three major sources of difficulty in learning physics as related: nature of subject, teaching/teacher factors and curriculum/assessment. Students were found to have difficulty understanding specific topics in the curriculum that are usually characterized as lacking concrete examples and requiring a lot of mathematical manipulations or visualization. Many also found difficult the tasks of solving problems alone and asking questions in class. The findings have implications for designing interventions and identifying pedagogical techniques that help students overcome the underlying sources of difficulty that impede quality learning.
\end{abstract}

\section{Introduction}

Physics is basic for understanding the complexities of modern technology, and essential for technological advancement of a nation. This aspect of science is making significant contribution to many of the inventions that are shaping modern day, and has helped to explain many of the events being encountered in everyday life. Despite its importance, physics remains the least favored science subject among students generally. Compared to other science subjects, only a few students choose to study physics at O-level and, subsequently, at higher degrees. In Nigeria universities for example, physics departments and Teacher Education in physics continue to witness paucity of students, which is the reason there is serious shortage of physics teachers in secondary schools. More often than not, physics is taught by teachers who specialize in science other than physics.
This is generating concerns among science educators, and researchers are increasingly exploring why students avoid the subject.

The literature is replete with studies suggesting that students generally regard physics as conceptually difficult, abstract, uninteresting, and "elite discipline only suitable for exceptionally talented and gifted pupils" [1-5]. Compared with other science subjects, students like physics less than chemistry and biology $[2,4,6$,$] . In a survey of why secondary school$ students in the United Kingdom are not interested in studying physics, the main reason offered by students is that they perceive physics to be a difficult/hard subject [3] and have lower expectations of their ability to accomplish physics tasks [5,6]. Moreover, it was observed that "students enter secondary schooling with an equal liking for biology and physics, but over the period of secondary schooling, whereas their liking for biology remains reasonably stable, their liking for physics declines...they perceive biology as interesting, physics as boring" [2]. In Nigeria, the evidence of low enrolment and massive failure in public examinations (Secondary School Certificate Examination (SSCE) and National Examinations Council NECO) in physics is indicative that many students have difficulty learning the subject. Consistently for five years, on the average, less than $30 \%$ of the total students registered for senior secondary school certificate examination (SSSCE) entered for physics. More disturbing is the low level of performance of students; on the average, slightly over $30 \%$ of the students who sat for Physics passed at the credit level compared to well over $40 \%$ in biology and chemistry.

Students' difficulty in physics has been attributed to various factors. In a study in USA, for example, three categories of factors were identified: factors "related to the students that they are capable of controlling, factors related to the course and factors inherent in the nature of physics" [7]. In an investigation among physics teachers and students in Singapore, teachers were found to hold the view that 
students are prejudiced that physics is difficult whereas students are of the view that the subject is too abstract to understand [8]. Besides, students have been found to have difficulty with the nature of the subject requiring special skills in navigating the variety of learning tasks like using equations/formulas, problem solving, theoretical/conceptual understanding, spatial reasoning, and experimentation [7,8, 9]. Students' learning difficulty is associated with the fact they have to contend with many representations - such as experiments, formulas and calculations, graphs, words, conceptual explanations - at the same time, and they have to make transformations among them [10]. As intoned by Reddish [10], "Physics as a discipline requires learners to employ a variety of methods of understanding ... the ability to use algebra and geometry and to go from the specific to the general and back. This makes learning physics particularly difficult for many students". Specifically in Nigeria, some of the reasons adduced for poor learning in physics include students' poor attitude towards physics, lack of motivation, poorly resourced teaching and learning environment, poor mathematical ability and poor teaching method $[11,12,13]$.

Educators agree that students learn best what they find understandable. Also, students' perceptions about a subject influence their understanding and learning of that subject $[14,15)$, and continuing study of the subject $[3,4]$. This is suggestive that a major reason underpinning students' participation in a learning task is their perception of it as interesting/boring, or easy/difficult, or relevant/abstract. There is evidence that students who find a subject interesting tend to choose it for further study $[3,4,5]$. Thus, for those students who perceive physics as difficult, studying it might just be routine and there is less likelihood that the knowledge will be beneficially utilized, not to mention continuing study. This has serious implications for building a pool of physicists that are required for shaping technological development, and in particular, physics teachers that would help to build foundation for the subject in school.

Most studies in Nigeria have focused on students' problems in physics in relation to their attitude, misconceptions and interest. Others have analyzed classroom instructional environment, interactions and teacher quality to evaluate student learning. However, for the mere fact that physics has been severally labeled as the most conceptually difficult science subject, it is important to explore the underlying difficulties that might impede quality learning in the subject in the context of Nigeria school environment. When teachers recognize these difficulties, it helps them to choose appropriate and efficient teaching methods and techniques. For the purpose of improvement of learning outcomes in Nigeria, this study is therefore aimed at providing insight into the aspects of physics that students consider as posing difficulty in secondary school physics, and the underlying reasons for the difficulty as it affects their learning.

\section{Method}

The sample comprised 830 (306 females and 524 males) final year students in science class and 52 physics teachers purposively drawn from schools in Ogun and Lagos State, Nigeria. The choice of final year students was based on the reason that after at least two years of studying the science subjects, they would be able to compare experiences across the subjects and form an opinion about physics. Students' views were gathered using a short questionnaire that contained both open and closedform items on which students indicated their views about the difficulty of physics as a school subject. Students were asked to indicate whether or not they find physics difficult to study, what constitute their difficulty and what specific aspects of the subject they find difficult to understand. Specifically, students were asked to indicate whether they will like to study physics as major subject after school. Also, students were asked to list any five topics that they have found most difficult (and yet to be understood) in the school syllabus. The opinions of the teachers were also gathered on the topics that they think present the most difficulty for students and which usually require extra effort to get them to understand. A closed-form item listing a variety of learning tasks in physics was also presented for students to indicate their view on liking to do it or finding it difficult. Finally, the teachers also indicated what they considered to make the subject difficult for students.

\section{Results}

Close to half of the students $(47 \%)$ consider physics interesting, and a majority (69\%) would not drop it if given a choice for a number of reasons. The most frequently cited reasons are that physics is 
compulsory for science option $(54 \%)$ or needed for future career program $(62 \%)$ or good performance $(42 \%)$ or enjoying it $(34 \%)$. Just a few indicated reasons of personal interest $(26 \%)$ and external (parental, teacher, peer) influence (19\%). However, about $58 \%$ consider physics a difficult subject and a disappointingly low proportion (18\%) would like to major in physics after school. Of those who consider it difficult, $47 \%$ and $53 \%$ were among male and female respectively. The distributions of responses between genders are not significantly different ( $p>$ $0.05, \chi^{2}$ test). The predominant aspects of physics learning that the students consider difficult (Table 1) are categorized into three: nature of subject, teaching/teacher factors and curriculum/assessment. The most frequently cited reasons are related to nature of the subject, including: too many calculations $(47 \%)$, problems not easy to solve (45\%), and too much hard/difficult content to recall (46\%). Quite a substantial proportion expressed difficulty in constructing meanings of the content when taught $(56 \%)$. Table 2 highlights the predominant views that the teachers hold on the underlying reasons for students' difficulty. Their views are mainly student-centred: mindset/attitude that the subject is difficult $(57 \%)$, weak mathematical skills required for solving problems (56\%), erroneous interpretation and answering of examination questions $(53 \%)$. Of note is that whereas the teachers identified reasons that are mainly related to the students, the students' views are more about the nature of the subject and teaching process. For instance, the teachers hold the view that competency in mathematics is a major impediment for students' competence in physics whereas the students do not give this serious consideration. Of note also is that the students considered examination questions difficult $(36 \%)$ whereas the teachers are of the view that the students' interpretation of questions is faulty.

The predominant difficult topics, indicated by at least $20 \%$ of the teachers, were pooled and used to analyze the students' responses. The percent of students' vis-à-vis teachers indicating each of the topics are shown in figure 1. The five highest listed topics that were considered difficult are: 1) energy quantization 2) AC circuit 3) electromagnetic field, 4) projectile, and 5) electric field. Figure 2 shows the students' views of specific learning tasks in physics. The predominant tasks that the students consider difficult doing are 1) solving problems alone 2) taking tests and examinations 3) asking questions in class, 4) doing calculations, and 5) asking for help from the teacher. They also do not enjoy doing calculations or asking question in class whereas they like to read physics textbooks, do practical, attend classes and solve problems with their mates.

Table 1. Predominant reasons for students finding physics difficult

\begin{tabular}{|ll|}
\hline Category of reason & $\%$ responses \\
\hline Nature of subject: & \\
$\begin{array}{l}\text { Too many formulae/laws/content } \\
\text { to memorize }\end{array}$ & 35 \\
Theoretical & 43 \\
Problems not easy to solve & 45 \\
$\begin{array}{l}\text { Too much hard/difficult } \\
\text { formulae/laws/concepts/contents }\end{array}$ & 46 \\
Content not easily understood & 41 \\
Too many calculations & 47 \\
Physics not enjoyable & 27 \\
Teaching/teacher: & 39 \\
Constructing meanings of \\
taught concepts
\end{tabular}

Percentages total more than 100 because individual students offered more than one reason. Data are given as a percentage of those thinking that physics is difficult 
Table 2. Teachers' views on why students find physics difficult

\begin{tabular}{|ll|}
\hline Category of reason & $\begin{array}{l}\% \text { responses } \\
\mathrm{n}=52\end{array}$ \\
\hline $\begin{array}{l}\text { Interpreting/answering questions } \\
\text { Mathematical skill for solving }\end{array}$ & 53 \\
Problems & 56 \\
Exposure to practical work & 45 \\
Seriousness/concentration in class & 38 \\
Reading habit & 31 \\
Use of textbook & 37 \\
Mindset/attitude & 57 \\
Learning environment & 38 \\
Foundation & 32 \\
Parental support & 28 \\
\hline
\end{tabular}

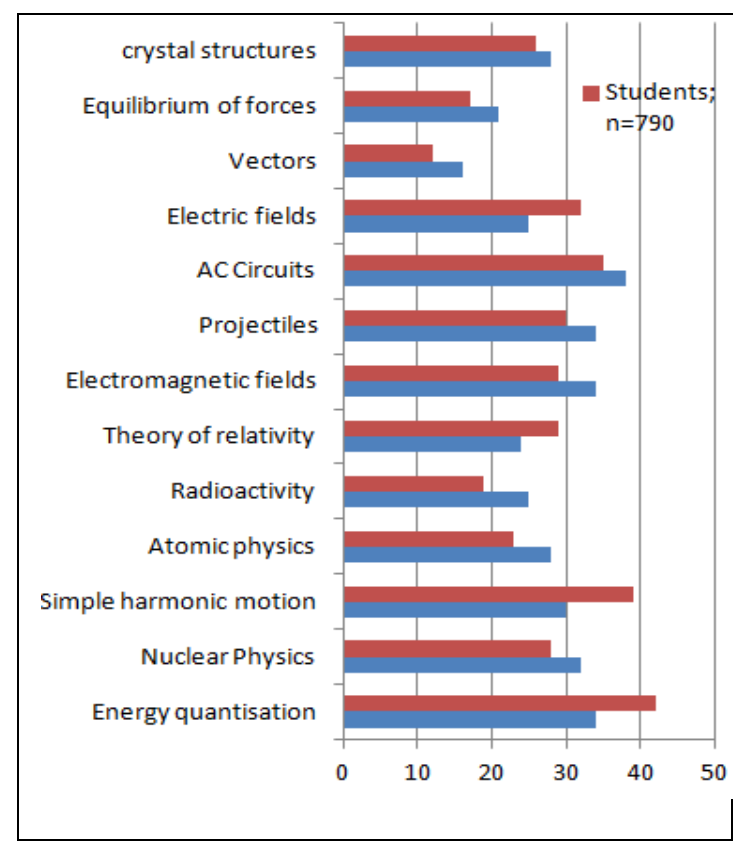

Figure 1. Pooled frequency (\%) of difficult physics topics indicated by teachers and students

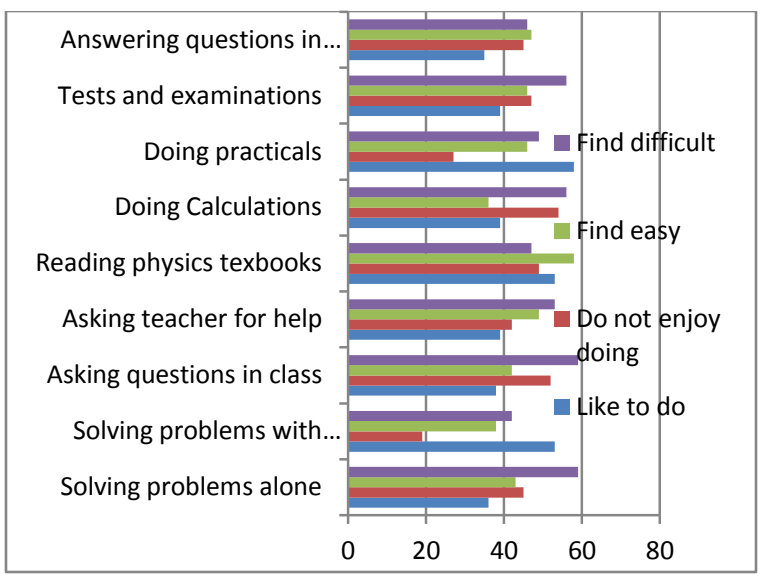

Figure 2. Pooled frequency (\%) of students' views of learning tasks in physics

\section{Discussion}

The findings indicate that many students would continue studying physics primarily because they find it useful for their future programmes, although only a few consider it a future major subject of study. This is an eye opener to a serious problem that requires urgent attention as students merely consider physics a 'service subject'. It is important therefore, to find out what makes physics a less worthwhile subject to study, and the point during schooling that students develop such impression. Low interest to continue to study physics is of concern because it has adverse effect on the contribution of the future generation to shaping the development of the nation. Of note is the finding that students consider physics interesting, though difficult. This outcome is consistent with results of other studies [2, 3]. For instance, the students indicated difficulty in solving problems, doing calculations and constructing meanings of taught concepts. The implication of not having conceptual understanding results in regurgitation, superficial learning and intuitive application of principles. Educators agree that students learn best what interests them, and meaningful content is better learned and retained than less meaningful content $[15,16]$. Therefore, for enhanced interest and learning in physics, students should be supported with instructional strategies that foster assimilation of learning materials rather than memorization. By providing concrete experiences in physics lessons, students would associate meanings to learning material and thereby achieve better understanding and retention of information. Even the 
supposedly abstract concepts would be better understood after a foundation of concrete and relevant information has been established. Furthermore, studies have shown that students learn physics better when qualitative understanding of underlying principles is established before introducing quantitative aspects as this takes them beyond routine application of formulae and equations.

Whereas the students tend to associate their difficulty with the difficult nature of physics problems, many of the teachers consider that inadequate mathematics competency of students is a major hindrance to their competency in physics. The literature also underlined the importance of competency in mathematics for physics [7, 8,9]. A previous study in Nigeria had also found that many students perform algorithmic or mathematical manipulation by rote memorization of formulae, without having a basic understanding of specific concepts and are therefore unable to construct meanings from the problem statement [12]. Therefore, instructional process in physics should include appropriate remedial activities that help students fill in the gaps in their problem-solving and mathematical skills. Students are found to enjoy physics if they know how to plan and implement the strategies of solution to questions.

One significant revelation from this study that requires attention is that the students are experiencing difficulty in understanding some topics. Apparently, the mostly cited difficult topics for the students (fig. 1) are topics that are usually characterized as abstract, loaded with symbolic representations, lacking concrete examples and requiring a lot of mathematical manipulations, visualization or conceptualization. Previous studies have also shown that these topics are perceived difficult by students either because of the complexities of the underlying principles or because of students' misconceptions that tend to create cognitive conflicts during learning. For example, the topic of waves is one that many high school physics students in the UK reportedly found difficult to understand [17]) - "students are unable to interpret common interpretations of sound waves, are unable to account for the underlying wave model of sound, or have no coherent model of the physics". Other studies [16, 17, 18] show that electromagnetic waves is considered the most difficult by high school graduates and physics teachers in Turkey, the reason being that the students are not capable of grasping the relationship between the creation of electric and magnetic fields [18]. Students are also found to have difficulty conceptualizing the wave-particle duality nature of photons [17]. Also, students are reported to experience difficult in relating the principles of probabilities and uncertainties in quantum physics [19]. According to Çalışkan et al [19] "the difficulty of learning quantum physics is primarily due to the fact that the students having been brought up in the tradition of classical physics, the fundamental concepts of which are determinism and causality, find it difficult to adjust to those principles of quantum physics i.e., uncertainty,,probability, etc”. Furthermore, just as the students in the present study indicated difficulty with projectile motion, secondary school students (and even teachers) in Australia were also found to experience cognitive conflicts in grasping the underlying principle of horizontal and vertical motion simultaneously in projectile motion [20].

From the responses of a few sample students that were interviewed to identify the underlying reason for the difficulty of the topics, the predominant reasons indicated are teacher-bound - poor instruction, lack of practical illustrations, inadequate coverage etc. Many students claimed that compared with other topics, their teacher appeared less confident in the explanations or glossed over the topics or avoided the topics completely. As many of the teachers of physics in secondary schools are not specialist physics teachers, it is not unlikely that they lack deep understanding of those topics, or the pedagogical knowledge required for teaching the topics meaningfully and connecting it to society to stimulate the interest of students to want to continue studying the subject. The challenge for physics educators in Nigeria is to support teachers, through research and workshops, with sound pedagogical content knowledge that make for understanding of the topics that are labeled as difficult so as to reduce learning frustrations among students.

\section{Conclusion}

Although this study is limited in terms of sample size, nonetheless, it has revealed the students' perception of physics as difficult subject which could be a reason that students develop declining interest in physics over the course of their secondary schooling. It is important therefore to alter the present image of physics and raise the standard of learning the subject by providing students with positive experiences in 
foundation physics. The findings that students do not like to ask for help from their teacher or answer questions in class are also noteworthy, requiring that teachers must emphasize active teaching methods (e.g., group work, cooperative learning and presentations) and friendly classroom environment that could initiate quality interactions between the students and with the teacher.

\section{References}

[1] Doug Checkley, High school students' perceptions of physics. A Thesis Submitted to the School of Graduate Studies of the University of Lethbridge, Alberta, Master of Education, 2010

[2] C. Ancell, O. Guttersrud, E., Henriksen, and A. Isnes, "Physics: Frightful, but fun. Pupils' and teachers' views of physics and physics teaching", Science Education, 2004, 88(5), 683-706

[3] C. Williams, M. Stanisstreet, K. Spall, E. Boyes, and D. Dickson, "Why aren't secondary students interested in physics?" Physics Education, 38(4), 2003, pp. 324-329

[4] J. Lavonen, V. Meisano, R. Byman, A. Uiito and K. Juiit, "Pupils interest in Physics: A survey in Finland", NORDINA, 2, 2005, pp 72-85

[5] Barmby P and Defty N 2006 Secondary school pupils' perceptions of physics Res. Sci. Technol. Educ. 24 199215.

[6] Watson J, McEwen A and Dawson S 1994 Sixth form A-level students' perceptions of the difficulty, intellectual freedom and interest of science and arts subjects Res. Sci. Technol.Educ. 12 (1) 43-51.

[7]Ornek F, Robinson W R and Haugan M P 2008 What makes physics difficult? Int. J. Environ. Sci. Educ. 3 30-4

[8] O. Funda, R. William, O Robinson, and P. Mark, " What makes physics difficult?" International Journal of Environmental \& Science Education, 2008, 3 (1), 30 - 34

[9] Oon P-T and Subramaniam R 2011 On the declining interest in physics among students - from the perspective of teachers Int. J. Sci. Educ. 33 727-46.

[10] E.F. Redish, "The implications of cognitive studies for teaching physics", American Journal of Physics, 62,1994, pp. 796-803.

[11] B. O. Ogunleye and V. F. T. Babajide," Generative instructional strategy enhances senior secondary school students achievement in physics, European Journal of Educational Studies 3(3), 2011, 453-63

[12] A.O. Ogunleye, “Teachers' And Students' Perceptions Of Students' Problem-Solving Difficulties In Physics: Implications For Remediation, Journal of College Teaching \& Learning, , 6, 2009, pp.785-796

[13] I.H. Harry, "Attitude of students towards science and science education in Nigeria (A case study of selected secondary schools in Rivers State)", Continental J. of Educational Research, 4(2), 2011, pp. 33-51

[14] Gebbels S, Evans S M and Murphy L A 2010 Making science special for pupils with learning difficulties $B r . J$. Spec.Educ. 37, 139-47.

[15] M.K. Smith,"The cognitive orientation to learning"'(online2007), www.infed.org/biblio/learningcognitive

[16] Esin Sahin and Rahmi Yagbasan, Determining which introductory physics topics pre-service physics teachers have difficulty understanding and what accounts for these difficulties, Eur. J. Phys. 33 (2012) 315-325

[17] Nakleh, "Improving Students' Understanding of Waves by Plotting a Displacement-Time Graph in Class.", The Physics Teacher, 50 (4), 2012, pp. 234-252.

[18] KesonenM H P, AsikainenM A and Hirvonen P E 2011 University students' conceptions of the electric and magnetic fields and their interrelationships Eur. J. Phys. 32 521-34.

[19] Serap Çalışkan, Gamze Sezgin Selçuk and Mustafa Erol, "Student Understanding of Some Quantum Physical Concepts". Lat. Am. J. Phys. Educ. 3( 2), May 2009.

[20] Anne Prescott and Michael Mitchelmore, "Teaching projectile motion to eliminate misconceptions",www.emis.de/proceedings/...PMEVol4Pr escottMitchelmore.pdf, 2005. 